\title{
Correction to: Non-oncological applications of RGD-based single-photon emission tomography and positron emission tomography agents
}

\author{
Thomas Ebenhan $^{1,2} \cdot$ Janke Kleynhans ${ }^{1,2} \cdot$ Jan Rijn Zeevaart ${ }^{2,3} \cdot$ Jae Min Jeong $^{4} \cdot$ Mike Sathekge $^{1}$ \\ Published online: 4 March 2021 \\ (C) Springer-Verlag GmbH Germany, part of Springer Nature 2021
}

\section{Correction to: Eur J Nucl Med Mol Imaging https://doi.org/10.1007/s00259-020-04975-9}

There was a mistake in the original article. The references cited in Table 1 to Table 4 are incorrect.

The correct set of references per table appears below.

Table 1 must rather refer to references $\mathbf{1 7}$ (first entry) to $\mathbf{2 7}$ (last entry) NOT 8 (first) to 18 (last)

Table 2 must rather refer to references 28 (first entry) to $\mathbf{6 1}$ (last entry) NOT 19 (first) to $\mathbf{5 2}$ (last)
Table 3 must rather refer to references 62 (first entry) to $\mathbf{6 5}$ (last entry) NOT 53 (first) to $\mathbf{5 6}$ (last)

Table 4 must rather refer to references $\mathbf{6 6}$ (first entry) to $\mathbf{7 2}$ (last entry) NOT 57 (first) to $\mathbf{6 3}$ (last)

The original article has been corrected.

Publisher's note Springer Nature remains neutral with regard to jurisdictional claims in published maps and institutional affiliations.

This article is part of the Topical Collection on Erratum

The online version of the original article can be found at https://doi.org/ 10.1007/s00259-020-04975-9

Thomas Ebenhan

thomas.ebenhan@up.ac.za

1 Nuclear Medicine, University of Pretoria, Pretoria 0001, South Africa

2 Nuclear Medicine Research Infrastructure, NPC, Pretoria 0001, South Africa

3 DST/NWU Preclinical Drug Development Platform, North-West University, Potchefstroom 2520, South Africa

4 Department of Nuclear Medicine, Institute of Radiation Medicine, Seoul National University College of Medicine, 101 Daehangno Jongno-gu, Seoul 110-744, South Korea 